\title{
Um novo modelo educacional através da TV Digital
}

\author{
Valter Roesler ${ }^{1}$, Maria L. K. Barbosa ${ }^{2}$, Cláudio D. Araujo ${ }^{1}$, Federico Wasserman, \\ Alexandro Bordignon ${ }^{1}$
}

${ }^{1}$ Instituto de Informática - Universidade Federal do Rio Grande do Sul (UFRGS)

Bento Gonçalves, 9500, Bloco IV - Porto Alegre, RS, Brasil

${ }^{2}$ CINTED - Universidade Federal do Rio Grande do Sul (UFRGS)

Av. Paulo Gama, 110/Bloco 12105 - 90.040-900 - Porto Alegre, RS, Brasil

\{roesler, cdaraujo, fwasserman, abordignon\}@inf.ufrgs.br, malukroeff@yahoo.com.br

\section{A new utilization of Digital Television in education}

\begin{abstract}
This paper presents a new model to the utilization of Digital TV in education, where the televiewer tunes an educational channel on TV and doesn't receive audio and video, like he/she is used to, but a list of educational courses. The courses description and their content are cyclically broadcasted in the educational channel. The proposed model was developed considering technical aspects regarding the system feasibility involving the SI tables, object and data carousel. In order to validate the model, the authors implemented an educational course named "Viva Saudavel" (Live Healthy).
\end{abstract}

Resumo. Este artigo apresenta um novo modelo para utilização da televisão digital em educação, onde o telespectador sintoniza um canal de televisão $e$ não recebe mais áudio e vídeo na forma que está acostumado, mas sim uma lista de cursos educacionais. A lista de cursos e seu conteúdo são transmitidos ciclicamente em broadcast para um canal educacional. O modelo proposto foi desenvolvido considerando os aspectos técnicos necessários para viabilização do sistema envolvendo as tabelas SI, carrossel de objetos e conteúdo. Os resultados obtidos mostraram a viabilidade e o diferencial da solução. Para validar o modelo, os autores implementaram um curso educacional denominado "Viva Saudável”.

Palavras-chaves: televisão digital, educação, televisão interativa, inclusão digital

\section{Introdução}

Educação através da televisão é um mecanismo que vem sendo utilizado de diferentes formas nas últimas décadas. Atualmente, a possibilidade de interagir com a programação é um dos recursos fundamentais buscado pelos educadores, que buscam na TV Digital Interativa (TVDI) um novo recurso didático-pedagógico a ser explorado. Nesse contexto, surge o conceito de t-learning, que poderia significativamente melhorar a aprendizagem para uma grande população de pessoas.

A TV Escola (MEC, 2009) é um canal do Ministério da Educação que tem como objetivos principais o enriquecimento do processo de ensino-aprendizagem e o aperfeiçoamento dos professores da Educação Básica. No ar desde 1996, é um canal de televisão brasileiro, transmitido via satélite por antena parabólica, e que transmite séries e programas educativos durante 24 horas diárias. Atualmente a programação já pode ser vista através da Internet também. 
Agregando interatividade ao TV Escola, surgiu em 2003 a TV Escola Digital Interativa (MEC, 2009b), onde o receptor digital entregue nas escolas armazena até uma semana de programação. Dessa forma, as escolas que receberem o receptor digital podem acessar os cursos gravados no disco rígido do mesmo. A proposta deste artigo vem aproximadamente nessa linha, porém modificando o conceito do conteúdo, que no TV Escola é de áudio e vídeo, e no modelo proposto é com a transmissão de diversos objetos de aprendizagem que formam cursos educacionais completos, permitindo separadamente ou conjuntamente animações, textos áudio e vídeo.

O Telecurso 2000 (2009), por sua vez, propõe duas opções de participação: uma delas é que o aluno frequente uma instituição cadastrada para receber acompanhamento de um professor, e a outra é que ele mesmo busque meios alternativos de tirar suas dúvidas. Em ambos os casos, o conteúdo é veiculado pela televisão convencional, em horários pré-determinados. No caso onde o aluno frequenta uma telesala, o professor deve estar presente durante a exibição do programa e realiza atividades e exercícios após o término da exibição do mesmo. No modelo proposto, não há necessidade do aluno sair de casa para ter acesso ao tutor, bem como estar presente em determinado horário para assistir ao programa. Ele pode definir o horário que deseja ver um determinado curso, e também tirar suas dúvidas com um professor disponível ou, então, interagir com outros participantes do curso através da própria televisão, caso a mesma tenha interatividade.

O projeto BEACON ${ }^{1}$, de educação a distância através da TV Digital, é um consórcio entre Brasil e Europa visando a transmissão de cursos complementares para a melhoria na formação da população, bem como oportunidades iguais para todos. $\mathrm{O}$ primeiro curso experimental a ser transmitido será de cursos pré-vestibulares, objetivando uma maior igualdade da população que pode pagar por cursinhos e os que não podem. Estes, no caso, teriam a oportunidade de receber o curso pré-vestibular em casa. A arquitetura do sistema BEACON é baseada na transmissão de aplicativos de TV Digital juntamente com uma programação exclusiva de áudio e vídeo voltada para o curso em questão.

O SAPSA (Serviço de Apoio ao Professor em Sala de Aula) é uma solução especificada pelo CPQD (2009) e se propõe a apoiar o professor na sala de aula com a apresentação de vídeos. Para tanto, o professor recebe um Terminal de Acesso e solicita (agenda) o dia, hora e vídeo que ele gostaria de mostrar aos alunos. Essa solicitação é transmitida via canal de interatividade, ocupando pouca banda. O vídeo em si, que ocupa mais banda, é transmitido via canal de broadcast, ficando disponível para toda a área de recepção do transmissor em questão. As diferenças do SAPSA para o paradigma proposto neste artigo são claras: o SAPSA, apesar de ser uma solução criativa, não objetiva a interatividade, nem é voltado para o ensino a distância, e sim para o ensino presencial.

Outras iniciativas também foram realizadas, sugerindo e apontando a convergência do atual E-learning para o T-learning como é o caso dos jogos educacionais (PINTO, 2008) e também da adaptação do Moodle para a TV Digital, fazendo com que o conteúdo seja reaproveitado e essa convergência implementada através de uma Application Programming Interface (API), adaptando esse conteúdo para a interface da TV Digital (FRANCO, 2007).

\footnotetext{
${ }^{1}$ http://www.beacon-dtt.com/en/index.php
} 
O modelo proposto neste artigo serve justamente para facilitar a aplicação desse tipo de solução, onde os programas estarão disponíveis a todo o momento, e existe uma integração com o ambiente de aprendizagem. A partir da requisição do telespectador, ele pode iniciar as atividades de aprendizagem. A seção 2 detalha a arquitetura da solução, enquanto a seção 3 apresenta os detalhes técnicos da implementação. Na seção 4, os resultados são apresentados e a seção 5 traz as conclusões.

\section{Detalhamento da Solução}

Atualmente a televisão digital possui as seguintes características relativas ao assunto deste artigo:

- A banda completa de um canal ISDB-Tb é aproximadamente $19 \mathrm{Mbit} / \mathrm{s}$;

- Um canal de televisão é, tipicamente, composto por pelo menos um sinal de áudio e vídeo;

- Os aplicativos de TV Digital transmitidos via carrossel de dados rodam sobre o sinal principal de áudio e vídeo;

- Áudio e vídeo ocupam grande parte da banda ocupada pela TV Digital. Um codificador H.264 pode ser configurado para utilizar bandas variadas. Tipicamente, utiliza-se $14 \mathrm{Mbit} / \mathrm{s}$ para transmissão HD e $4 \mathrm{Mbit} / \mathrm{s}$ para transmissão SD.

O modelo proposto neste artigo modifica as características acima para um canal educacional específico a ser criado, da seguinte forma:

- O canal de televisão educacional não transmite sinal de áudio e vídeo, economizando essa banda;

- Neste canal, são transmitidos dezenas de cursos simultâneos e independentes;

- Esses cursos podem ser armazenados no receptor, permitindo que sejam cursados assincronamente.

Assim, quando o telespectador sintoniza esse “canal educacional”, ele não vai receber áudio e vídeo no modo tradicional e, com isso, toda banda do espectro poderá ser utilizada para transmitir uma grande variedade de cursos, chegando ao receptor e podendo ser armazenados e utilizados à semelhança de um ambiente virtual de aprendizagem livre. Um possível canal para esse objetivo seria o canal da educação, de responsabilidade do Ministério da Educação ${ }^{2}$. Nesse caso, os cursos existentes hoje no portal do professor poderiam migrar para a televisão digital.

A utilização de um servidor educacional configurado com um ambiente de aprendizagem (como o Moodle, por exemplo), permite concentrar os debates entre os estudantes com a mediação do tutor. Pelo modelo dos autores, o conteúdo do curso é recebido através do canal broadcast e o canal de interatividade não obrigatoriamente necessita ser banda larga, porém, faz-se necessária sua presença. A utilização do mesmo é basicamente para a comunicação por texto ou áudio com o tutor e colegas.

A Figura 1 mostra a visão geral da solução proposta. A emissora do canal educacional de TV transmite constantemente uma quantidade de cursos relacionados a conhecimentos gerais, como português, matemática, geografia, etc. Outra opção é a grade de programação segmentada de acordo com o perfil de cada região. Por exemplo, numa região com riscos de Dengue, Febre Amarela e DSTs, os cursos podem ser relacionados a mecanismos de prevenção de doenças; em regiões com muitos obesos,

\footnotetext{
${ }^{2}$ http://portal.mec.gov.br/
} 
podem ser transmitidos, entre outros, cursos de alimentação e vida saudável; já em regiões agrícolas, podem ser transmitidos cursos sobre técnicas de plantio e colheita.

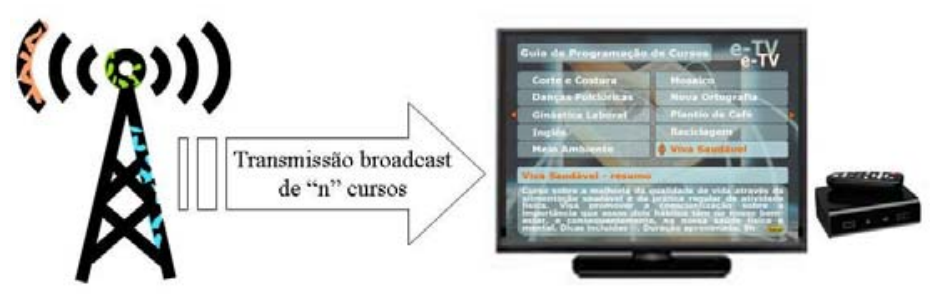

Figura 1. Visão genérica da solução.

O “guia de programação" de cursos consiste, basicamente, do índice e apresentação de cada um dos cursos transmitidos, buscando maior participação da população para determinar quais os novos cursos que serão enviados, após esses transmitidos por um tempo suficientemente longo. A Figura 2a apresenta um exemplo do portal, que é a tela inicial desse guia. Podem-se visualizar, por ordem alfabética, 10 (dez) possíveis cursos para o telespectador, que também terá acesso a outras possibilidades através das setas para a esquerda e direita. Além disso, o mesmo tem a autonomia para escolher os cursos que deseja salvar no dispositivo de armazenamento de massa (pen drive, disco rígido, etc). Porém, para que isso aconteça, é necessário pressionar o botão amarelo ("Salvar"), e a partir desse momento, o curso começa a ser armazenado na memória do terminal de acesso, sendo completamente carregado depois de alguns minutos, conforme detalhamento na sequência do artigo.

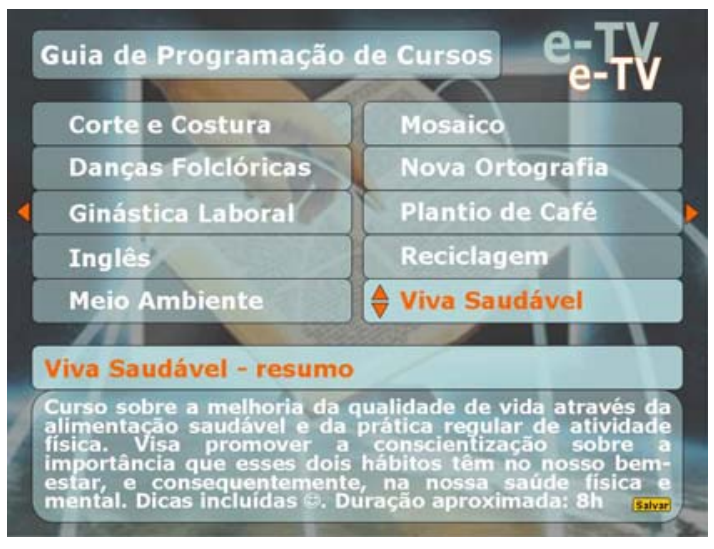

(a) Guia de programação

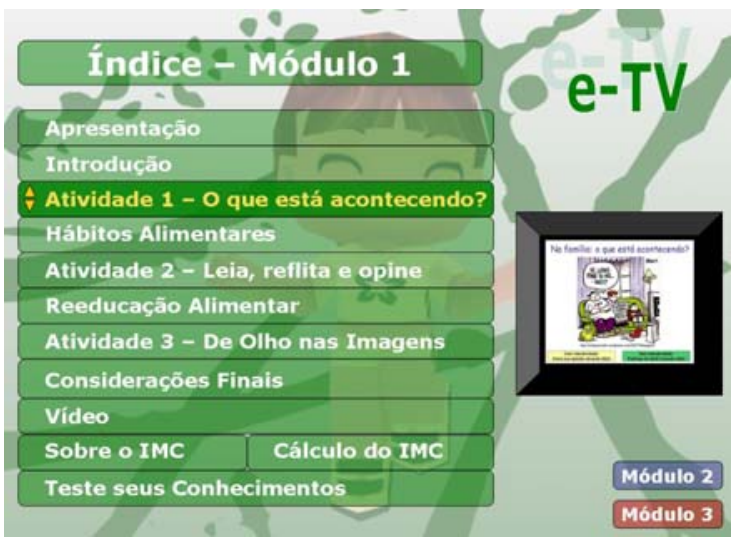

(b) Índice do curso "viva saudável"

Figura 2. Exemplo de tela de guia de programação e índice de um curso.

Quando o usuário decide ver mais detalhes de um determinado curso e seleciona o mesmo, o resumo desse curso é apresentado. A Figura $2 \mathrm{~b}$ mostra detalhes do curso "Viva Saudável”, apresentados ao usuário caso o mesmo fosse selecionado.

O receptor do usuário (Terminal de Acesso) é equipado obrigatoriamente com um dispositivo de armazenamento de massa. Recomenda-se que seja um pen drive ou equivalente, devido à sua alta escala que já provocou um barateamento no preço, tornando-se disponível para praticamente qualquer usuário. Considerando que cada curso ocupe na sua totalidade, em média, 100 MBytes, com texto, imagens, vídeos e animações, um pen drive de 2 GB conseguirá armazenar até 20 cursos completos.

Porém, os cursos não precisam ser limitados a transmissões de texto, imagens, animações, áudio e vídeo, podendo e devendo conter objetos de aprendizagem envolvendo exercícios, aplicativos com interatividade local com o usuário, e mesmo 
aplicativos com interatividade global com um servidor de ambiente de aprendizagem, como o Moodle 3 .

O Curso Viva Saudável, desenvolvido pelos autores, possui 3 (três) módulos, com cerca de 20Mbytes cada. Está previsto para ser cursado entre seis e oito horas. Se considerarmos que os módulos contiverem em média de 20 a 30Mbytes cada e que os cursos na íntegra tenham cerca de 100MBytes, conforme já mencionado, a transmissão do módulo introdutório de cada curso pode ser enviada cinco vezes ou mais por ciclo no carrossel de objetos. A Figura 3a mostra uma tela de aplicativo de TV Digital onde o usuário interage localmente, mostrando a atividade 1 - “O que está acontecendo?”.

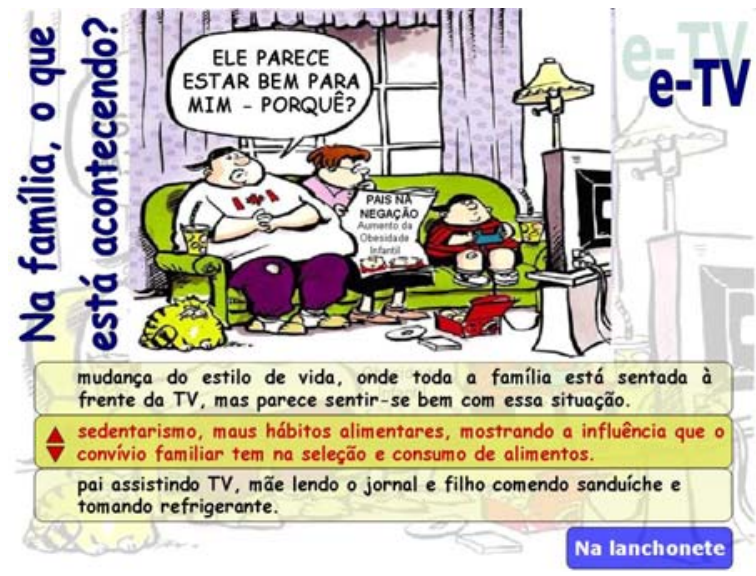

(a) Interatividade Local

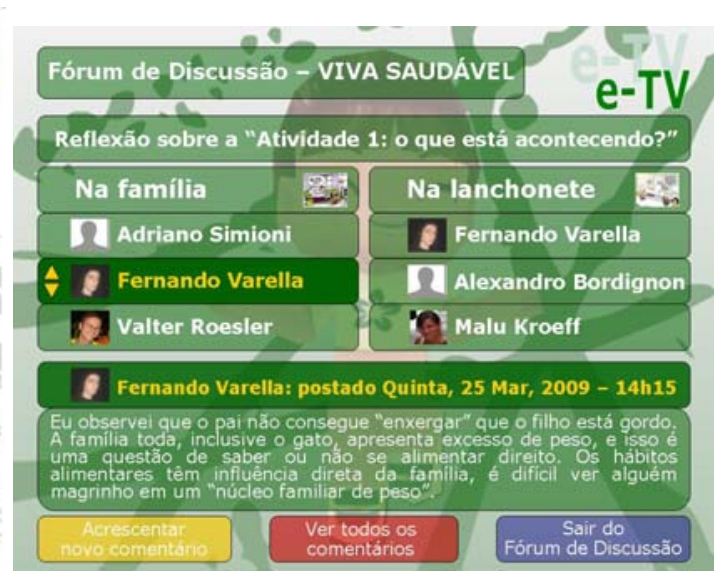

(b) Interatividade Global

Figura 3. Interatividade local e global.

A Figura 3b mostra uma tela de aplicativo onde o usuário interage globalmente. Para isso, o conteúdo do curso solicita uma interação num fórum de discussão entre alunos diversos que estão fazendo o curso. O aluno, nesse caso, pode ler os comentários postados e inserir sua opinião a respeito do assunto abordado. Como diversos alunos de diferentes localidades participam, ocorre uma interação e troca de opiniões entre eles, abordando diferentes aspectos do conteúdo, de acordo com a visão de cada um e enriquecendo o aprendizado.

Atualmente os set-top boxes são equipamentos com baixo poder de processamento, e as emissoras não estão utilizando uma banda superior a 1Mbit/s na transmissão de aplicativos, entretanto, com o avanço da tecnologia esse quadro tende a mudar, e este artigo assume a utilização de set-top boxes que suportem a recepção e gravação de $19 \mathrm{Mbit} / \mathrm{s}$, o que não é uma taxa muito elevada em termos de sistemas embarcados.

\section{Implementação do Sistema}

A implementação e validação do sistema foi dividida em quatro áreas distintas: a) transmissão broadcast; b) implementação do portal com persistência dos dados; c) definição do diretório de cursos; d) implementação do curso "Viva Saudável”, para prova de conceito. As subseções a seguir detalham cada uma dessas áreas.

\footnotetext{
${ }^{3}$ http://moodle.org/login/index.php
} 


\subsection{Transmissão Broadcast}

A transmissão televisiva (broadcast) envolve a criação das tabelas SI (Service Information) adaptadas para o envio de cursos. Duas tabelas essenciais em toda transmissão broadcast são a PAT (Program Association Table) e a PMT (Program Map Table) (ABNT, 2008). Conforme ilustrado na Figura 4, uma transport stream tem uma única tabela PAT que através do PID (Packet Identifier) aponta para diversas PMTs. Cada PMT, por sua vez, indica o PID das diversas streams elementares (seja de vídeo, áudio, legendas ou dados) que compõem um determinado programa.

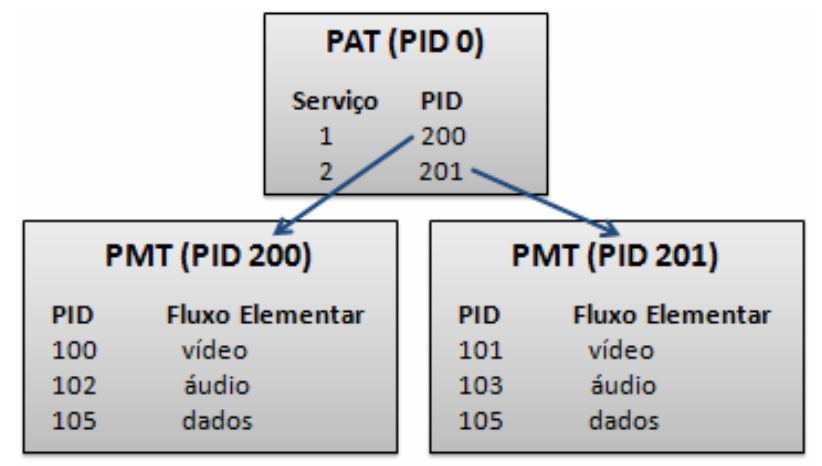

Figura 4. Tabelas PAT e PMT. Adaptado de (MONTEZ e BECKER, 2005).

Neste artigo, propõe-se que cada PMT represente o PID de um curso. Desta forma, quando o set-top box efetuar a gravação de um curso, basta gravar num diretório do dispositivo de armazenamento o PID associado ao curso. A transmissão broadcast dos cursos é cíclica, ou seja, ao final do envio do conjunto completo dos cursos, o sistema passa a transmitir o conjunto novamente a partir primeiro arquivo, por isso, essa transmissão foi batizada de "carrossel de conteúdo", a fim de diferenciar da transmissão do "carrossel de dados", onde é efetuada a transmissão do aplicativo “portal”.

A norma ABNT NBR 15606-3 (ABNT, 2008) lista os tipos de transmissão de dados, que são: PES independente; Carrossel de dados/objetos; Mensagem de eventos; Protocolos de canal de interatividade; Encapsulamento multiprotocolo e Data piping. De todos os tipos de especificação, o mais adequado para a implementação tanto do carrossel de conteúdo como do carrossel de dados é o tipo "carrossel de dados/objetos". A norma ABNT considera a implementação do carrossel em uma ou duas camadas. É utilizada uma camada quando os parâmetros de todos os módulos cabem em uma única mensagem DII - DownloadInfoIndication - ou são semelhantes o suficiente para se enquadrarem na mesma categoria (ETSI, 2003). Pela simplicidade de sua estrutura e número limitado de cursos oferecidos simultaneamente, o "Carrossel de Conteúdo" proposto pode ser implementado usando o carrossel de dados de uma camada. No caso do SI, o descritor data_broadcast_descriptor deverá estar presente no SDT ou no EIT, ou seja, seu uso é obrigatório quando existir o carrossel de dados. No caso do PSI, o descritor data_broadcast_id_descriptor poderá estar presente no PMT, ou seja, seu uso é opcional.

\subsection{Implementação do Portal}

De acordo com as especificações da ABNT em relação ao middleware de TV Digital Ginga-NCL, utilizou-se a linguagem declarativa NCL - Nested Context Language (NCL, 2009) e a linguagem script Lua (PUC RIO, 2009). 
Quando o usuário sintoniza o canal educacional proposto, o Terminal de Acesso recebe o aplicativo "portal” a partir do carrossel de objetos e o executa automaticamente como aplicativo principal, dessa forma, rapidamente ele já visualiza uma interface com a qual pode interagir. Buscando a simplificação do processo, e aproveitando o fato do aplicativo NCL já ser enviado através do carrossel de objetos, a solução escolhida para a implementação do portal referente ao recebimento de novos cursos, bem como dos que já estariam presentes no pen drive, foi a de receber as informações dos cursos em um arquivo texto, ligados diretamente à aplicação do portal. A solução utilizada para a edição do documento NCL, com os cursos recebidos do carrossel de objetos e do pen drive, foi a utilização de eventos de fluxo NCL, juntamente com as bases privadas do Ginga-NCL e NCL Live Editing commands (SOARES et al, 2009).

Dentre os comandos de edição para o Gerenciador da Base Privada Ginga, podem-se citar como principais para este estudo o addDocument, removeDocument, startDocument e stopDocument. O comando addDocument adiciona um documento NCL a uma base privada, sendo que ele pode ser enviado no carrossel de objetos como sistemas de arquivo, recebido pelo canal de interatividade como sistemas de arquivo, ou ser sistemas de arquivo já residente no receptor. O comando startDocument inicia a reprodução de um documento NCL em uma base privada e começa a apresentação a partir de uma interface específica do documento. Os comandos removeDocument e stopDocument fazem o inverso, removendo ou parando um documento da Base Privada, respectivamente (ABNT, 2006). Para o propósito deste artigo, cada documento NCL referenciado pelo portal é o início de um dos cursos. Dessa forma, quando o usuário selecionar um curso no portal, o script Lua gerenciador do portal adicionará o documento relacionado ao curso à base privada e iniciará o curso.

Em relação ao aplicativo portal em si, pode-se dizer que o mesmo é composto de um arquivo NCL, um script Lua, algumas imagens, como as utilizadas para o fundo e também para os botões. O arquivo NCLua do aplicativo portal possui em sua estrutura uma lista de apontadores para todos os cursos que estão disponíveis no carrossel de conteúdo, e essa lista relata todos os arquivos NCL de cada curso, ou seja, cada curso possui obrigatoriamente um arquivo NCL que define a apresentação do mesmo. É importante destacar que cada curso deverá possuir um ID único, para que seja possível identificá-lo no gerenciador de conteúdos do receptor digital e no pen drive, evitando assim apresentar duas vezes o mesmo curso no portal, um por ter vindo via broadcast e outra por estar armazenado no pen drive.

\subsection{Implementação do diretório de cursos}

Segundo a norma ABNT NBR 15606-2 (2006), aplicações NCLua podem salvar dados em uma área restrita do middleware e recuperá-los entre execuções. O exibidor Lua permite a uma aplicação NCLua persistir um valor para ser posteriormente usado por ela ou por um outro objeto procedural. Para tanto, o exibidor define uma área reservada, inacessível a objetos NCL não procedurais. Essa pode ser a primeira área a ser utilizada para registro dos cursos armazenados, desde que o receptor possua algum mecanismo de armazenamento em massa. Nesse cenário, uma vez gravado o curso no set-top box, qualquer estudante que o utilize terá acesso aos cursos gravados. Embora o mecanismo persistent já esteja presente na norma brasileira, ainda não há implementações do mesmo nos ambientes de testes disponíveis e, portanto, ainda não pode ser testado o armazenamento e indexação no próprio set-top box. 
Referente ao armazenamento dos cursos em um pen drive, a linguagem Lua (PUC-RIO2009) disponibiliza a biblioteca “io", que disponibiliza funções de gerenciamento de arquivos, como leitura e gravação. Porém a norma cita que essa biblioteca está dentre as funções removidas da linguagem Lua para a TV Digital, por ser dependente de plataforma. Para que a solução de armazenamento proposta neste artigo seja viável, será necessário que algum mecanismo de leitura e gravação esteja disponível nos set-top boxes disponíveis comercialmente. No escopo deste artigo, para a criação de um protótipo para validar a solução proposta, as funções da biblioteca "io" foram utilizadas. No momento que set-top boxes forem disponibilizados no mercado, essas funções deverão ser substituídas por seus equivalentes funcionais.

\subsection{Implementação do curso "Viva Saudável”}

As mesmas observações realizadas para implementação do portal em relação ao uso do Ginga-NCL são válidas nesta seção.

A implementação do curso Viva Saudável foi o primeiro passo para se adquirir a base que possibilitasse os testes de maneira real. Esse curso visa a conscientização da população em relação a hábitos saudáveis, ou seja, é um curso sobre a melhoria da qualidade de vida através da alimentação saudável e da prática regular de atividade física, proporcionando ganhos para a saúde física e mental. Destina-se a jovens entre 12 e 15 anos, mas não é restrito a outras faixas etárias. Com o conteúdo do curso em mãos, passou-se para o estágio de desenvolvimento, que, primeiramente, ocorreu em ambientes de simulação e, posteriormente, em um set-top box, validando efetivamente a usabilidade das aplicações. Utilizou-se o XHTML para a confecção do aplicativo, visto que é uma recomendação W3C tanto para Web como para dispositivos móveis, e na TV Digital é recomendado para compatibilidade com os diversos padrões de TV Digital existentes no mundo (ABNT, 2006).

\section{Resultados Obtidos}

O tamanho total da implementação do aplicativo "Portal" em NCL foi de 200 kbytes. Como não temos uma transmissão broadcast de televisão, partimos do ponto que o aplicativo portal já está carregado no set-top box. A Figura 5 apresenta a tela implementada do portal, que buscou os cursos a partir de um arquivo no próprio aplicativo, conforme detalhado anteriormente, efetuando somente a implementação do curso Viva Saudável.

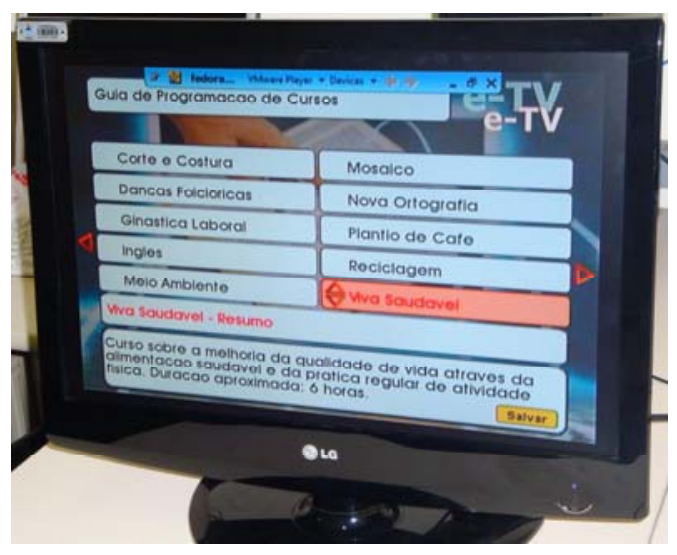

Figura 5. Tela inicial do aplicativo portal implementado.

Uma função NCLua lê um arquivo texto e armazena os dados de cada curso lido. As informações foram agrupadas em um padrão de seis linhas, onde cada linha 
corresponde a uma informação distinta e a ordem dessas linhas foi padronizada da seguinte forma para essa versão: a primeira linha contém o identificador do curso, a segunda linha o título do curso, da terceira à quinta linha um breve resumo do curso e por fim, na sexta linha, o caminho relativo que identifica a localização do conteúdo do curso. Essa solução foi adotada por ser extremamente simples de ser processada e só conter as informações essencialmente necessárias para o Portal, requisitos importantes quando se trata de equipamentos limitados como set-top boxes. O conteúdo lido do arquivo fica armazenado em estruturas de dados Lua.

A Figura 6 ilustra o código responsável por efetuar a leitura do arquivo texto e armazenar os dados nas estruturas de variáveis id, title, resume (3 linhas) e path, para posterior acesso, viabilizando a navegação e chamada dos cursos implementados.

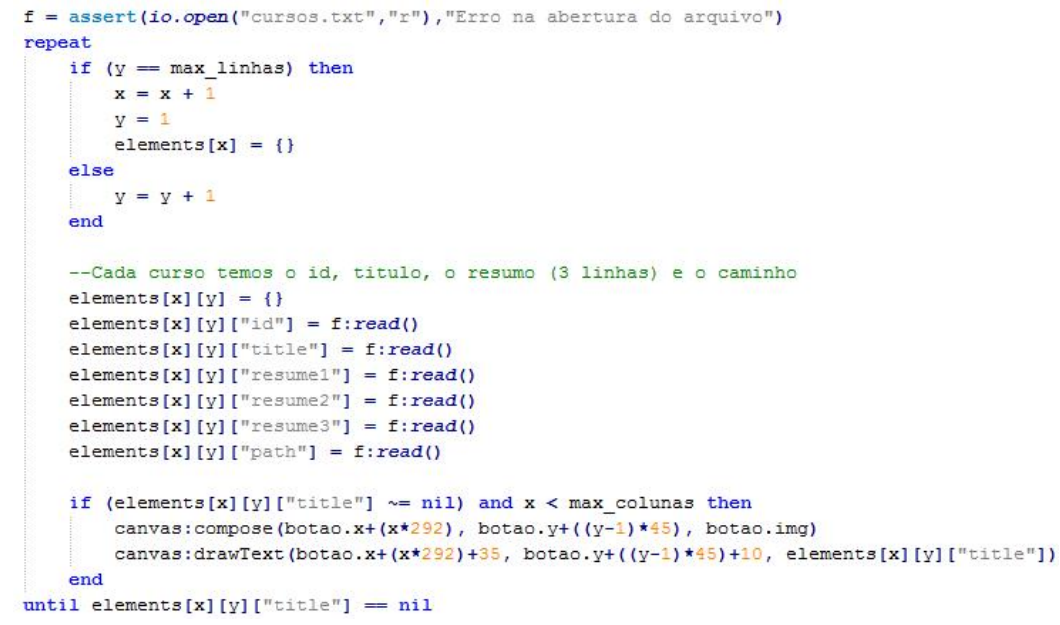

Figura 6. Código NCLua que lê o arquivo de cursos.

O tamanho desse módulo implementado foi de aproximadamente 40 Mbytes, o que é coerente com o tamanho estimado, de aproximadamente 100 Mbytes por curso. A Figura 7 apresenta imagens do curso na tela da televisão.
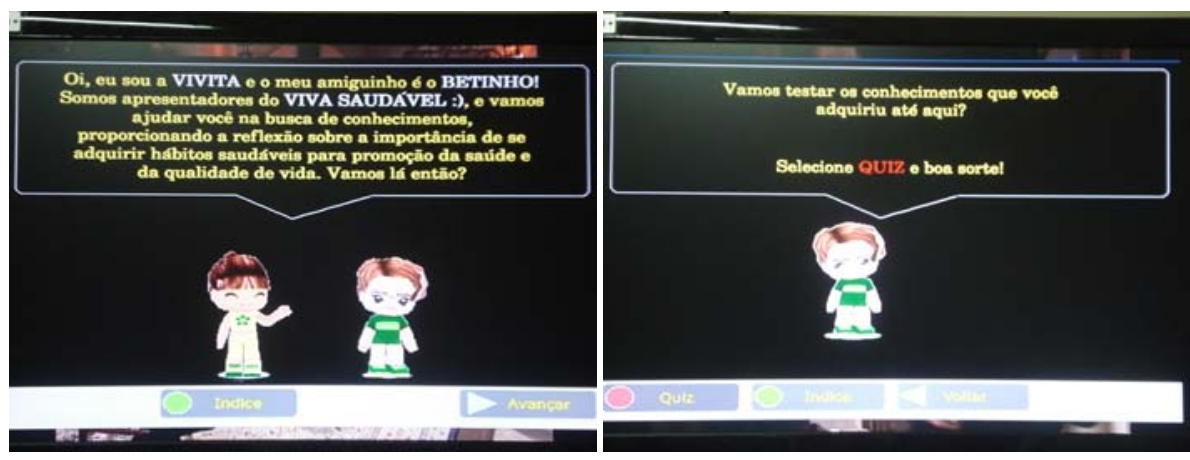

Figura 7. Exemplos de tela do curso Viva Saudável.

Como os NCL Live Editing Commands ainda não estão implementados nas versões do Ginga-NCL disponíveis, ao invés de adicionar os documentos NCL de cursos dinamicamente, esses já foram inseridos no aplicativo portal.

\section{Considerações Finais}

A contribuição deste artigo para a comunidade científica é clara e o modelo foi validado, permitindo continuidade em diversas áreas e possibilitando educação de forma distribuída para toda uma população carente de conhecimento. Dessa forma, faz valer a intenção governamental com a criação da TV Digital, contemplando a inclusão social 
através da inclusão digital. No modelo de paradigma apresentado, um canal educacional é criado e diversos cursos são transmitidos em broadcast. Além disso, o estudante pode, através do canal de interatividade, efetuar interação com o curso de forma local (interação através de animações e questionários), ou mesmo de forma global, participando de fóruns de discussão e debates descentralizados com tutores, à semelhança de cursos a distância na web.

As principais dificuldades foram a falta da biblioteca "io" e de um ambiente de transmissão composto de multiplexador e servidor, para mapear os PIDs e gerar o carrossel de conteúdo com os PIDs apropriados. Mesmo assim, o artigo possui muitos desdobramentos futuros, a idéia central é válida e a implementação efetuada prova isso.

\section{Referências bibliográficas}

ABNT NBR 15603-1. Televisão digital terrestre - Multiplexação e serviços de informação (SI) Parte 1: SI do sistema de radiodifusão. 2008.

ABNT NBR 15606-2. Televisão digital terrestre - Codificação de dados e especificações de transmissão para radiodifusão digital Parte 2: Ginga-NCL para receptores fixos e móveis - Linguagem de aplicação XML para codificação de aplicações. 2007.

ABNT NBR 15606-3. Televisão digital terrestre - Codificação de dados e especificações de transmissão para radiodifusão digital Parte 3: Especificação de transmissão de dados. 2008.

CPQD - Centro de Pesquisa e Desenvolvimento em Telecomunicações. Disponível em http://www.cpqd.com.br. Acesso em dez. 2009.

ETSI TR 101202 V1.2.1 Digital Video Broadcasting (DVB); Implementation guidelines for Data Broadcasting. 2003.

FRANCO, Barbara B. B.; OLIVEIRA, H. C. Proposal for Convergence of E-learning Systems for T-learning. ICL2007 Conference, Villach: Austria, 2007.

MEC. Ministério da Educação. TV Escola. Disponível em http://portal.mec.gov.br/tvescola/. Acesso em jan. 2009.

MEC. Ministério da Educação. TV Escola Digital Interativa. Disponível em http://www.idbrasil.gov.br/noticias/News_Item.2003-12-16.5818. Acesso em dez. 2009.

MONTEZ, Carlos; BECKER, Valdecir. TV Digital Interativa: conceitos, desafios e perspectivas para o Brasil. Florianópolis: Ed. da UFSC, 2005. $2^{\mathrm{a}}$ edição.

NCL - Nested Context Language. Disponível em http://www.ncl.org.br. Acesso em jul. 2009.

PINTO, Lady D. O.; NETO, José P. Q.; LUCENA JR, Vicente F. An Engineering Educational Application Developed for the Brazilian Digital TV System. $38^{\text {th }}$ ASEE/IEEE Frontiers in Education Conference, NY, 2008.

PUC-RIO. Lua 5.1 Reference Manual. Disponível em http://www.lua.org/manual/5.1. Acesso em dez. 2009.

SOARES, L.F.G; RODRIGUES, R.F; Costa, R.R.; MORENO, M.F. Part 9 - NCL Live Editing Commands. Technical Report. Departamento de Informática PUC-Rio, No. 36/06. 2006. Disponível em http://www.ncl.org.br. Acesso em mai. 2009. 
Telecurso 2000 - Sistema de Educação Brasileiro por Televisão. Disponível em www.telecurso2000.org.br. Acesso em dez. 2009. 